\title{
O silêncio em A paixão de Joana D'Arc
}

\author{
Tatiane Monteiro da Cruz' \\ https://orcid.org/0000-0002-5832-2833
}

\author{
Adilson Mendes" \\ https://orcid.org/0000-0002-3258-494X \\ I - Instituto Federal de São Paulo. \\ São Paulo (SP). Brasil. \\ II - Universidade Anhembi Morumbi. \\ São Paulo (SP). Brasil.
}

Resumo: O artigo aborda o filme A paixão de Joana D'Arc (1927) de Carl-Theodor Dreyer, que buscou representar o estado de graça da personagem icônica, recorrendo ao uso exaustivo do primeiro plano (como evidenciado por sua vasta fortuna crítica), mas também optando por uma ambiência completamente silenciosa, que torna o filme ao mesmo tempo um documento fidedigno ao fato histórico e uma obra artística com densa organicidade. A descrição de momentos significativos da obra é amparada em referências historiográficas (Johan Huizinga e Alain Corbin) e teóricas (José Moure).

Palavras-chave: cinema mudo; Carl-Theodor Dreyer; história do cinema; A paixão de Joana D'Arc.

\begin{abstract}
The Silence in The Passion of Joana D'Arc - The paper addresses the film The Passion of Joana D'Arc (1927), by Carl-Theodor Dreyer, which sought to represent the state of grace of the iconic character, resorting to the exhaustive use of the foreground (as evidenced by his vast critical fortune), but also choosing a completely silent ambience, which makes the film both a reliable document to the historical fact and an artistic work with dense organicity. The description of significant moments of the work is supported by historiographic references (Johan Huizinga and Alain Corbin) and theoretical references (José Moure and John Cage).
\end{abstract}

Keywords: silent film; silence; Carl-Theodor Dreyer; cinema's history; The Passion of Joana D'Arc. 
Por trás da maquiagem, a atitude, por trás dessa aparição encantadora e moderna havia algo. Havia uma alma por trás da fachada. E para vê-la bastaria retirar a fachada.

Para mim era, antes de tudo, a técnica do processo verbal que comandava. Havia, de início, esse processo, com suas vozes, sua técnica própria, e foi essa técnica que tentei transmitir no filme. Havia as questões, havia as respostas - muito curtas, muito claras. Não havia outra solução que os primeiros planos por trás das réplicas. Cada questão, cada resposta, exigiam naturalmente um primeiro plano. Era a única possibilidade. Isso decorria da técnica do processo-verbal. Além disso, o resultado dos primeiros planos era que o espectador receberia os mesmos choques que Joana, recebendo as questões e torturada por elas.

No teatro você tem as palavras. E as palavras preenchem o espaço, permanecem no ar. É possível escutá-las, sentilas, provar seu peso. Mas no cinema, as palavras são muito rapidamente relegadas a um segundo plano que as absorve, e é por isso que é preciso guardar apenas o absolutamente necessário e essencial.

[Carl-Theodor Dreyer. Entre Terre et ciel-entretien avec Carl-T. Dreyer par Michel Delahaye. In: Cahiers du cinéma, n.170, setembro, 1965]

Este artigo visa retomar questões fundamentais da estética cinematográfica dos anos 1920 a partir da análise do filme A paixão de Joana D'Arc [La passion de Jeanne D'Arc, 1927] de Carl-Theodor Dreyer. O fato do filme partir do processo-verbal, uma fonte que preserva as características orais do fato histórico, nos fez notar o uso particular do silêncio, aspecto praticamente negligenciado pela crítica histórica, que se deteve, sobretudo na questão do primeiro plano, nos significados artísticos do rosto e sua consequente reformulação do espaço fílmico. O trabalho mais consistente publicado no Brasil sobre toda a obra de Dreyer (ERBER, 2012) destaca a especificidade do silêncio no filme sobre a santa guerreira. Em sua tese, A captura dos corpos falantes no cinema de Carl Th. Dreyer, Laura Rabelo Erber afirma:

Se, para a poesia romântica, o silêncio era encarado como o desafio da realização do sublime, para os escritores modernistas, ele se converteu na busca do indizível e do irrepresentável, ora entendido como promessa ora como o verdadeiro terror da linguagem do qual já nenhum escritor seria capaz de escapar. O silêncio ressurgiu, assim, inquietando uma literatura que já nascia sob o signo da perda da plenitude expressiva, num contexto marcado pela consciência da saturação da linguagem e pela ideia de que ao escritor restava bem pouco para ser dito. (ERBER, 2012, p. 7) 
A autora se detém na questão do silêncio e a expande para outros filmes de Dreyer, o que fortalece sua argumentação sobre seu uso como procedimento artístico. A erudição enciclopédica do trabalho permite ilações sobre o silêncio, Dreyer e a literatura contemporânea, opondo a concepção romântica à de Dreyer que, segundo a autora, estaria mais próximo das vanguardas históricas do século XX. No presente artigo, nos concentramos exclusivamente em um único filme, para extrair de sua forma os efeitos específicos produzidos pelo silêncio. E neste sentido, diferentemente da autora, nos voltamos para fontes ligadas ao universo místico, especialmente Soren Kierkegaard (KIERKEGAARD, 1974) e Max Picard (PICARD, 2006), que oferecem possibilidades teóricas de abordagem do silêncio no princípio do século XX. Para Picard, o silêncio é a continuidade da fala, do ruído, do barulho.

Como uma modalidade de sentido, o silêncio faz emergir uma interioridade, sendo tomado por esses autores como substância tangível que se impõe à atenção. E nesse sentido, nos parece importante compreender como o filme de Dreyer está ligado também a fontes históricas, visto que a communio medieval é, ao mesmo tempo, mística e comunicativa.

Tal dualidade é proposta pela mistura de um processo-verbal com o silêncio, linguagem sob um fundo silencioso que marca o limite, o fim da linguagem. Essa rara dualidade presente num filme nos inquietava. Para George Steiner, o

[...] mais elevado e puro grau do ato contemplativo é aquele em que se aprendeu a abandonar a linguagem. O inefável encontra-se além das fronteiras da palavra. Somente com a ruptura das muralhas da linguagem a prática visionária poderá penetrar no mundo da total e imediata compreensão. Quando se alcança tal compreensão, a verdade não precisa submeter-se às impurezas e à fragmentação que a fala necessariamente acarreta. Não precisa ajustar-se à lógica ingênua e à concepção linear do tempo implícitas na sintaxe. Na verdade final estão compreendidas, simultaneamente, o passado, o presente e o futuro. É a estrutura temporal da linguagem que os mantém artificialmente distintos. Esse é o ponto crucial. (STEINER, 1988, p. 30)

A questão do silêncio é tratada em diversos âmbitos na reflexão sobre a linguagem artística ao longo do século XX, possuindo inúmeros aspectos, assim como a própria noção de linguagem. O silêncio é muitas vezes tomado como parte da linguagem, mas também como seu contrário, ou até mesmo sua condição de possibilidade. São fartos os exemplos na arte moderna e 
principalmente na música, cujo nome mais expressivo é John Cage, que nos ampara aqui com suas concepções originais (CAGE, 1973).

Em relação à estética cinematográfica, a presença do silêncio é frequentemente destacada no cinema sonoro em razão do contraste produzido pelo meio, mas raros são os estudos sobre o silêncio no chamado cinema "mudo". Buscamos assim, por meio de um caso singular, evidenciar a originalidade de Carl-Theodor Dreyer ao compor sua obra-prima em uma atmosfera marcada pelo silêncio absoluto.

Se é certo, como afirma o teórico Michel Chion, que no cinema feito nas primeiras décadas do século XX “[...] não era o personagem de cinema que era mudo, era o cinema que Ihe era surdo [...], que dava ao espectador [...] o olhar do surdo" (CHION, 2004, p. 18), nesse cinema o espectador assiste a pessoas que se falam, que se compreendem uns aos outros, reagem auditivamente ao mundo exterior, enquanto o próprio espectador é privado da escuta. Por essa razão, o silêncio era dificilmente representado. Como afirma um dos raros comentadores do silêncio no cinema desse período, José Moure, o silêncio “aparecia para o cinema mudo como um significado sem significante, ao mesmo tempo inaudível e impossível a se transpor na ordem do visível" (MOURE, 1998, p. 27). Assim, o silêncio encontrava nos filmes convencionais apenas um modo de expressão enviesado e indireto.

- Os exemplos de parada do movimento, um sino que interrompe repentinamente seu badalar, o estancamento sonoro súbito que cria um suspense dramático numa cena de uma atração circense, sugerem ao espectador o silêncio no mundo diegético. Em sua classificação, Moure apresenta pelo menos cinco diferentes tipos de silêncio no cinema (mudo e sonoro): o silêncio técnico saído do mundo fabricado, produzido pela supressão da banda sonora, e percebido apenas pelo espectador;

- $\quad$ o silêncio de orquestra se manifestando pelo retraimento da música de acompanhamento, e percebido apenas pelo espectador (cf. os momentos nos filmes de Hitchcock, como por exemplo Intriga Internacional, Os pássaros, Um corpo que cai e principalmente Marnie, as confissões de uma ladra, quando a aparição musical de Hermann se interrompe totalmente para permitir uma condensação do drama);

- $\quad$ o silêncio de ambiência (ausência de ambiência sonora) caracterizado pela interrupção ou suspensão de barulhos provenientes do mundo de referência e percebido apenas pelo espectador (cf. as numerosas 
passagens dos primeiros filmes de Jean-Luc Godard: O pequeno soldado, Uma mulher é uma mulher, em que os personagens passeiam pelas ruas movimentadas sem que o barulho da cidade apareça na banda sonora);

- o silêncio diegético (ou narrativo) existente no mundo de referência do filme, e ouvido por um ou diversos personagens (cf. os primeiros minutos de $O$ Eclipse, de Antonioni, em que Monica Vitti e Francisco Rabal se confrontam sem pronunciar uma única palavra, tendo como fundo sonoro um ventilador; a célebre cena de Os pássaros antes do ataque à escola, onde Hitchcock mostra os pássaros se reunindo em silêncio sem que ninguém os perceba);

- o silêncio subjetivo em que tudo é situado no presente do filme, tudo está ligado ao universo de crenças ou ao sistema perceptivo de uma personagem (cf. O fugitivo, de Mervyn LeRoy, em que Paul Muni, o herói, enfia a cabeça na água para não ouvir os cachorros que o perseguem e, assim, faz com que o espectador também mergulhe no silêncio).

A paixão de Joana D'Arc parece não se incluir em uma única dessas definições, misturando principalmente o silêncio subjetivo com o silêncio diegético. Desde sua aparição nos meios do cinema de vanguarda, o filme de Dreyer chamou atenção por suas qualidades pictóricas, que exigiam um reposicionamento do espectador em relação à linguagem convencional. No calor da hora, o crítico Léon Moussinac, por exemplo, nos informa que a "[...] supressão da pintura dá aos rostos uma força estranha, terrível, que mostra singularmente o jogo interior dos sentimentos" (MOUSSINAC, L. apud SADOUL, 1963, p. XX). O que se nota no comentário de Moussinac é a primazia do rosto como elogio da especificidade da linguagem do cinema, que à época buscava marcar suas diferenças com certa noção de teatro, visto apenas como "arte da palavra". Para os vanguardistas do cinema da década de 1920, o rosto, como transparência, captava a essência da fisionomia da personagem e esse recurso só era possível graças ao primeiro plano cinematográfico, que explorava as sutilezas da expressão. A ênfase no elemento pictórico orienta, desde então, os comentários sobre o filme, ignorando completamente a função do silêncio como elemento constitutivo da estética criada por Dreyer que, salvo engano, permite uma condensação máxima da intensidade dramática, além de possuir ligações com a vontade de fidelidade histórica apresentada pelo realizador, como se verá adiante.

O rosto é tratado pela estética cinematográfica desde seus primórdios. Em seu livro O homem visível (1924), Béla Balázs já desenvolvia um tipo de 
fenomenologia da percepção em que o corpo, e sobretudo o rosto, possuía lugar de destaque. Para o teórico, o primeiro plano era a novidade da arte do cinema, que constituía uma nova percepção do mundo. ${ }^{1}$ Tomando como exemplo o rosto da atriz Lilian Gish, Balázs afirmava que o recurso técnico permitia a superação da descrição do mundo físico para representar o mundo mental. Dessa forma, Balázs avançava e transpunha para o cinema a reflexão do sociólogo Georg Simmel sobre o rosto nas artes plásticas, para quem

[...] a impressão de espiritualidade é reforçada pelo fato de que o rosto é muito menos submetido à gravidade que as outras partes do corpo. A figura humana é o lugar em que as pulsões psico-fisiológicas lutam com a gravidade do corpo físico, e o jeito de conduzir esse combate, de retomálo a cada instante, é determinante para o estilo no qual se apresentam o singular e o típico. Quando a necessidade de superar esta carga puramente corporal não está marcada no rosto, a espiritualidade da impressão se encontra reforçada. (SIMMEL, 1988, p. 140)

A multiplicidade de expressões unidas no rosto faz com que essa parte do corpo humano se compare à própria noção de obra de arte. Dessa forma, o rosto parece se destacar do espaço para remeter ao mundo interior ou ao transcendente. Essa concepção vai nutrir toda a teoria do cinema, de Balázs, passando por Eisenstein (1957) - para quem o primeiro plano desnaturaliza o espaço - e Pascal Bonitzer (1971), que nos anos 1970 reafirma o antinaturalismo do procedimento, chegando até a Gilles Deleuze, para quem a "[...] a expressão de um rosto e a significação dessa expressão não têm nenhuma relação ou ligação com o espaço. Diante de um rosto isolado, não percebemos o espaço. Nossa sensação do espaço é abolida. Uma dimensão de outra ordem abre-se para nós" (DELEUZE, 1983, p. 136).

Mais recentemente, o teórico Jacques Aumont, não por acaso, inicia seu estudo seminal sobre o rosto no cinema destacando a importância do filme de Dreyer para o tipo de reflexão desenvolvido por Jean-Luc Godard em Viver a vida (1962). Diz Aumont:

Assim, nenhum lugar de imagem, mais do que o rosto, foi sensível às variações históricas das noções de representação e de imagem. Na imagem medieval, o rosto se separa de valores de semelhança analógica para se tornar um signo, um símbolo. O homem é a imagem de Deus, por isso

1 Béla Balázs, como "clássico", aparece em inúmeros manuais de teoria do cinema, mas só recentemente teve uma edição crítica organizada por Erica Carter (2010), em que se localiza o contexto de suas formulações 
Deus adquire aparência humana. Por consequência, todo rosto vale exclusivamente por sua referência ao divino, escamoteando o referente humano, o rosto do homem aqui embaixo é apenas engano das aparências. É apenas quando emerge todo o conjunto da crença no homem (elaborada, mais lentamente do que frequentemente se diz, para desembocar na categoria do sujeito), a epifania do olhar e o culto das aparências visíveis, abrindo a via à fase moderna da noção de representação, que o rosto toma seu papel atual. (AUMONT, 1992, p. 16)

De maneira compreensível, os comentadores do filme de Dreyer seguiram à risca a teoria do cinema e seu destaque para o rosto, mas sem mencionar o silêncio como elemento estruturante da obra. Até mesmo seu mais atento comentador contemporâneo passa ao largo da questão, a nosso ver, nada acessória. Segundo David Bordwell, nas fontes já mencionadas acima, o filme de Dreyer rejeita as relações dominantes entre a lógica narrativa e o espaço cinemático característico do começo do século XX (BORDWELL, 1973, 1981)2, e a ênfase na representação do rosto parecia contestar o movimento típico do cinema narrativo. A força das imagens dos primeiros planos e a constituição particular de um espaço narrativo foram devidamente destacadas pela pletórica bibliografia sobre o filme de Dreyer. ${ }^{3}$

A recepção ao filme de Dreyer ao longo das décadas parece seguir de maneira inconsciente uma antiga concepção sobre a imagem pictórica, que teria origem em Leonardo da Vinci. Para o grande artista, ao contrário das obras literárias, os quadros não falam. Por isso, a pintura era para ele uma "poesia muda", que o fazia sugerir àqueles seus alunos que desejassem representar o espírito de uma personagem, que observassem os movimentos e gestos dos mudos, como se neles se encontrassem menos artifícios, expressões em puro estado mental. (CHASTEL, 1987, p. 246)

O filme de Dreyer frequentemente é mencionado como um bom exemplo de invenção de uma gramática visual própria. Porém, aqui nos parece que essa gramática original está associada ao uso construtivo do silêncio. ${ }^{4}$ No lugar de repisarmos esse debate sobre a composição imagética do filme,

2 Para uma leitura com mais densidade histórica, que supera o binarismo de Bordwell — vanguarda vs. classicismo - e sugere uma intrincada teia histórica sobre a disputa pela representação da figura de Joana D'Arc — canonizada em maio de 1920 (O'BRIEN, 1996).

3 É vasta a bibliografia sobre o filme de Dreyer. Aqui destacamos apenas algumas referências em português: AUMONT (2004); GODARD (1989).

4 São raros os filmes que se decidem pelo silêncio por opção estética. Do período silencioso destacamos A Rua (1923), de Karl Grûne, assim como certos filmes feitos por Stan Brakhage ou Nikolas Klotz, já no período do cinema falado. 
optamos por destacar um aspecto negligenciado: o fato do filme ter sido concebido sem qualquer som. O filme é completamente mudo e uma trilha sonora foi incluída de forma duvidosa no começo da década de 1950, sob a responsabilidade do crítico e historiador Lo Duca (DROUZY, 1987, p. 3-6). Em depoimento à historiadora Lotte Eisner, Dreyer reage à sonorização produzida pela Gaumont em 1953:

Eu sabia que meu ritmo seria destruído, não é o ritmo da música de um Bach, de um Beethoven. Isso me espanta que o verdadeiro texto do processo não serve mais de "pausa rítmica", pois no filme mudo os intertítulos eram mais que uma explicação, eles eram incorporados organicamente, tal como as pilastras em um edifício. Eu adoraria que uma cópia muda, tal qual o filme foi concebido, seja guardada em sua integralidade na Cinemateca Francesa, uma cópia sem cortes. (EISNER, 1955, p. 5) [Grifo nosso]

Apesar da reação do realizador, o filme foi exibido ao longo de décadas com acompanhamento musical sem se destacar a função estruturante do silêncio. Somente em 1981, foi encontrada uma cópia mais próxima do projeto original de Dreyer. E é esta versão que nos serve aqui de base para explorar a questão do silêncio. Até mesmo um observador tão atento como David Bordwell insiste em ignorar esse aspecto nada acessório. Em A paixão de Joana D'Arc, o silêncio tem uma função intensiva, em que a obra abala o tipo de escuta do espectador, produzindo uma função simbólica a todos os gestos e coisas. O silêncio absoluto desempenha o papel de um significante de conotação que retira a representação de sua lógica tradicional denotativa. Lugares, coisas e gestos remetem a um além de suas presenças concretas, configurando-se em símbolos. O silêncio em A paixão de Joana D'Arc funciona como um som indicial que se faz notar como silêncio atmosférico, que afeta a experiência do espaço e sua organização óptica.

Vejamos como isso ocorre na primeira parte do filme, quando Joana D'Arc presta seu primeiro depoimento aos juízes e clérigos. Como numa cena do teatro raciniano, toda a cenografia e o figurino - concebidos pelo célebre Hermann Warm - são despojados ao máximo para a obtenção do maior rendimento do pathos. Após os letreiros informarem sobre o precioso documento do processo-verbal depositado na Biblioteca Nacional Francesa, vemos o manuseio dos livros que serviram de fonte a Dreyer, que os reproduziu com grande exatidão (VIEIRA, 2009). Um lento travelling apresenta o espaço religioso dividido por soldados e clérigos até que Joana nos é 
introduzida. O primeiro plano evidencia seu incômodo diante da situação. Suas vestimentas sóbrias contrastam com a pompa clerical e as fardas da soldadela. Isolada entre lanças e acorrentada pelos pés, ela estranha tudo. A chegada de uma bíblia, selada também por correntes, sugere uma ligação profunda entre a figura feminina e a palavra divina. Seu olhar absorto contrasta com os gestos mundanos de seus juízes, enquanto o primeiro letreiro informa: "Eu juro dizer a verdade, toda a verdade..." Em seguida, o olhar severo de um clérigo faz par com a mirada altiva de um soldado inglês.

Começa então a série de campo e contracampo que vai opor a face de Joana ao corpo do bispo Cauchon, o responsável pelo interrogatório. Mais uma vez, o olhar absorto contrasta com os gestos irônicos dos religiosos. Esse olhar penetrante da personagem sugere que ela busca, em silêncio, amparo divino, visto que sempre olha para o alto, esperando aprovação antes de responder. Diante da exigência de uma fé protocolar, irrompe o choro sem fim da personagem. A leve inclinação da cabeça reforça a ideia da mulher santa diante do sarcasmo oficial. A singeleza das respostas de Joana se reveste de profundidade e causa espanto nos religiosos e indignação nos soldados ingleses que, em raro movimento de câmera, recuam e aproximam. Novo travelling e Joana é vista de joelhos diante de um dos clérigos. A transcendência de Joana é estática em relação ao mundanismo dos clérigos em movimento. ${ }^{5}$ A potência de sua palavra toca alguns padres e seu primeiro depoimento é interrompido. Mais um travelling e uma trapaça é armada.

Assim começa o filme de Dreyer, bem ao gosto dos interessados na canonização de Joana e sua transformação em modelo para a nação francesa. Não por acaso, Robert Brasillach, antissemita confesso e um dos primeiros historiadores do cinema, vai louvar os méritos do filme. Para além da aproximação da imagem da moça pobre, desprovida de erudição supérflua e com sentimentos puros, imagem também desejada pela extrema direita francesa (interessada na junção de catolicismo e patriotismo na década de 1920), o que foi destacado pela fortuna crítica sempre relacionou o filme com os usos dos primeiros planos para exploração da dimensão transcendental 
da imagem. O que nos interessa aqui é sobretudo a maneira como a ausência de som integra o estilo e o conduz à dramatização da introspecção de maneira radical, sendo ao mesmo tempo uma evidência da fidelidade histórica do realizador e um aspecto artístico consequente. Como nos informa o historiador Alain Corbin, durante os séculos XV, XVI e XVII, o silêncio aparece como condição indispensável a qualquer relação com Deus, visto que a meditação, a oração e a reza o exigem. "A tradição monástica transmitiu, desde a Antiguidade, uma ars meditandi que sai dos claustros do século XVI e que constitui, desde então, uma disciplina interior acessível ao laicos" (CORBIN, 2018, p. 66).

Na sequência da câmara de tortura, depois de ser enganada pelo sacerdote Loiseleur,que tenta convencê-la a abjurar por meio de uma carta forjada, supostamente assinada pelo rei Carlos VII, e após se recusar a retirar seu traje masculino, Joana é submetida a novo interrogatório. Novamente sua postura hierática, frequentemente captada em contre-plongé, contrasta com os travellings e o rictus facial de seus juízes, cujas expressões parecem criar uma extensão das máquinas de tortura acionadas pelos soldados. A imagem da corrente retorna e se liga às máquinas de tortura em movimento. Assombrada, ela resiste à pressão de seus juízes. "Mesmo se os senhores me separarem a alma do corpo, eu não me entregarei." Diante dos instrumentos de tortura em movimento, Joana desfalece. Mais uma vez as múltiplas texturas do silêncio potencializam o drama da proximidade da morte, da mesma forma que se apresenta como um gesto político, pois Joana está diante de uma força repressora que a obriga a falar e a impede de calar. “Desse modo o silêncio de Joana D'Arc é uma esquiva, uma tentativa de driblar os poderes embutidos na linguagem" (ERBER, 2012, p. 201).

O silêncio, como ato político, foi estudado por Eni Orlandi ao analisar discursos censurados, mas não é na censura que o silêncio de Joana se insere, mas como um discurso subversivo que ganha voz e poder, pois ela se recusa a fazer juramentos mais abrangentes e apresenta um discurso profético, que desestabiliza os juízes, fazendo com que recorram ao ardil para enganá-la e condenar.

[...] há duas formas de silêncio nesse filme: a omissão deliberada de informações por parte dos acusadores e as respostas que Joana D'Arc evita ou se recusa a dar. Essas duas formas de silêncio só podem ser entendidas dentro da lógica do abuso de poder jurídico no estabelecimento/ produção da verdade. (ERBER, 2012, p. 204) 
Ao comentar o crepúsculo da Idade Média, Johan Huizinga nos lembra o quanto a sensibilidade religiosa do período se mantinha sóbria na representação do divino.

\begin{abstract}
A insuficiência dos modos de expressão vai sendo aceita pouco a pouco. Abandona-se primeiro a brilhante representação do simbolismo e as fórmulas demasiadamente concretas do dogma. Mas a contemplação do Ser absoluto permanece ainda ligada à noção de extensão ou da luz. A seguir estas noções transferem-se para as suas contrárias — o silêncio, o vácuo, a escuridão. (HUIZINGA, 1985, p. 166)
\end{abstract}

Na mesma página, citando Mestre Eckart, o grande historiador fala ainda em "divindade silenciosa e tremenda". Em sua origem e fatura, o filme de Dreyer está empenhado em confirmar Joana D’Arc como santa.

Na sequência em que Joana tem seus cabelos cortados e, sozinha, reflete sobre sua tentativa de salvar a própria vida e se arrepende do gesto, o silêncio apresenta uma outra textura, explorando dimensões de sua consciência e reforçando seu vínculo com o sagrado. A sequência se abre com um plano de cabelos que tombam no chão. Em seguida, vemos Joana a chorar enquanto um soldado Ihe extirpa os cabelos. Um corte nos traz a movimentação popular que se forma fora da prisão. Novamente por meio de travellings o movimento externo é mostrado, com funâmbulos apresentando seus espetáculos a um povo excitado. Joana permanece indiferente aos movimentos bruscos do soldado que lhe corta os cabelos, com a cabeça pendida. Um primeiro plano a mostra absorta. Novo corte para os cabelos cortados no chão, varridos pelo soldado que cumpriu sua tarefa. Retorno do primeiro plano com Joana a refletir imóvel. Novamente o plano dos cabelos sendo recolhidos do chão. Mais um primeiro plano de Joana, que agora esboça uma reação por meio da ligeira mudança de seu olhar, que se volta para o soldado. Com vassoura e pá, o soldado recolhe os cabelos e, também, uma coroa improvisada, que evidentemente faz referência à coroa de espinho imposta ao Cristo pelos soldados romanos.

No filme de Dreyer tudo é símbolo e prefiguração. Com a cabeça frequentemente pendida - que a liga à tradição da Mater dolorosa (a mulher que presencia a morte de seu filho, ao mesmo tempo em que contempla o início de uma nova era), ela é a própria figura da mediação (PELEKIN, 2000). Por sua vez, o anel retirado à força pelos soldados é a analogia do estupro, assim como os velhos monges são a ortodoxia escolástica hipócrita, enquanto 
os jovens teólogos, especialmente Massieu (interpretado por ninguém menos que Antonin Artaud), representam a piedade e o reconhecimento do divino que se irradiam pelo mundo após a morte da "santa". Da mesma forma, os espaços, mesmo tão sóbrios, reproduzem bem a ambiência de clausura e punição, assim como as armas e as correntes figuram a dominação dos corpos, enquanto as vestimentas são o invólucro das almas. A depuração do fato histórico é total, ao mesmo tempo em que a fidelidade aos acontecimentos é rigorosa.

Ainda sobre a sequência do corte dos cabelos, a exposição em primeiro plano do rosto de Joana gradativamente revela o movimento de sua autorreflexão em direção à recusa absoluta da abjuração. Em rara gesticulação rápida, Joana clama ao soldado pela presença dos juízes, que chegam de súbito para ouvir sua recusa. Sempre plácida e a verter lágrimas, ela encontra pela primeira vez a correspondência de seu olhar em Massieu, cujo lânguido olhar reconhece sua santidade. A partir do experimento de John Cage com uma câmera anecoica - espaço construído para impedir a entrada de som externo, de forma a reverberar somente a produção de som ocorrida dentro da câmera - dir-se-ia que, nesse momento de autorreflexão silenciosa, é possível ouvir o sistema nervoso e a circulação sanguínea de Joana.

Para concluir, podemos reiterar a importância dos primeiros planos excepcionais em $A$ paixão de Joana D'Arc e seu consequente abalo da lógica espacial do cinema de convenções, e ainda acrescentarmos a função estruturante do silêncio para a lógica interna da obra. O silêncio - como elemento ligado ao sagrado, segundo a tradição cristã - é aqui concebido para expandir o drama a seu extremo e informar sobre o estado psíquico e extra físico da personagem. Nesse sentido, o filme se liga a uma tradição pictórica já explorada pela fortuna crítica do filme, mas também a partir da questão do silêncio podemos aproximá-lo de uma tradição literária contemporânea ao filme que relaciona espaço e psique ao silêncio. Como nos lembra Alain Corbin, certos lugares - como o claustro, a igreja e a cela prisional - respiram o silêncio que impregna suas paredes.

E um contemporâneo de Dreyer que vai tirar o máximo partido do silêncio para a literatura francesa é Georges Bernanos, que na juventude cristã foi ativo militante da Action Française, um grupo de extrema direita que via na figura de Joana D’Arc a junção possível da Pátria com a Monarquia. Em 1926, Sous le soleil de Satan (BERNANOS, 2010) foi um acontecimento literário 
de público e crítica, e seu início evidencia o quanto a questão do silêncio estrutura o romance e é significativa para a própria estética de Bernanos. Vejamos como se abre o romance:

É a hora vesperal, a amada hora de P.J. Toulet. Dissolve-se o horizonte; aos últimos raios do sol, uma grande nuvem branca, cor de marfim, paira no céu crepuscular e do zênite ao solo: a solidão imensa, gelada, cheia dum silêncio líquido... É a hora do poeta que destilava a vida em seu coração para extrair-lhe a essência secreta, perfumada, envenenada. O turbilhão humano com mil braços e mil bocas já se agita na sombra; o bulevar fervilha e deslumbra ... e ele, recostado à mesa de mármore, olha a noite subir, como um lírio. (BERNANOS, 2010, p. 10)

Nesse romance marcado pelo sentimento religioso, o silêncio é a hora decisiva, em que o mundo se revela por inteiro ao relato poético. Em outro romance, Monsieur Ouine, Bernanos analisa o silêncio que tem relações com a decoração dos interiores. Não por acaso, um dos romances desse autor — Diário de um pároco na aldeia - foi adaptado por Robert Bresson, outro cineasta responsável pela atualização do drama de Joana D'Arc. Da mesma forma, outro escritor francês, Joris-Karl Huysmans, busca o silêncio por meio de personagens atraídos em particular pelo silêncio que reina nas igrejas e em certas capelas obscuras, afirmando assim o quanto o silêncio faz par com a liturgia. Assim, além da exploração dos vínculos com certa tradição pictórica, o filme de Dreyer ainda está para ser relacionado com tendências da literatura do período que destacam o silêncio como uma experiência da contemporaneidade.

Tatiane Monteiro da Cruz é docente da área de libras e Língua Portuguesa no Instituto Federal de São Paulo e doutoranda na Universidade Anhembi-Morumbi. É autora de O surdo no cinema: mudanças de paradigma.

tatyany001@gmail.com

Adilson Mendes é pós-doutorando na Universidade Anhembi-Morumbi e historiador pela Unesp, com doutorado na Universidade de São Paulo.

adilsonmendes9@gmail.com 
Contribuições de cada autor: Tatiane: fundamentação teórica; escrita - revisão e edição; investigação de campo, metodologia, análise formal do corpus; Adilson: supervisão e gestão do projeto de pesquisa; fundamentação teórica; escrita - primeira redação; investigação de campo, metodologia, análise formal do corpus.

\section{Referências}

AUMONT, J. Du visage au cinema. Paris: Etoile/Cahiers du Cinéma, 1992.

O olho interminável - cinema e pintura. São Paulo: Cosac \& Naify, 2004.

BALÁZS, B. Béla Balázs: Early Film Theory. New York: Berghahb, 2010.

BERNANOS, G. Sob o sol de Satã. Tradução de Jorge de Lima. Rio de Janeiro: Realizações, 2010.

BONITZER, P. Le gros orteil. Cahiers du cinéma, Paris, n. 232, outubro 1971.

BORDWELL, D. Filmguide to La Passion de Jeanne D'Arc. Bloomington: Indiana University Press, 1973.

The films of Carl-Theodor Dreyer. Califórnia: University of California Press, 1981.

CAGE, J. Silence. Connecticut: Wesleyan University Press, 1973.

CARTER, E. Béla Balázs: Early Film Theory : Visible Man and The Spirit of Film. Tradução de Rodney Livingstone. Nova York - Oxford: Berghahn Books, 2010.

CHASTEL, A. Traité de la peinture de Léonard. Paris: Berger - Levrault, 1987.

CHION, M. La voz en el cine. Madri: Catedra, 2004. 18 p.

CORBIN, A. A History of the Silence - From the Renaissance of the Present Day. Londres: Politty Press, 2018.

DELEUZE, G. L'Image-Mouvement. Paris: Éditions de Minuit, 1983.

DELTEIL, J. Oeuvres Complètes. Paris: Bernard Grasset, 1961. p.626

DROUZY, M. A qui appartient la Jeanne D'Arc de Dreyer? 1895 - revue d'histoire du cinéma, n. 3, p. 3-6, 1987.

EISENTEIN, S. The film sense. LEYDA, Jay (org.). New York: Meridian, 1957.

EISNER, L. Rencontre avec Dreyer. Cahiers du Cinéma, n. 48, 1955.

ERBER, L. A captura dos corpos falantes no cinema de Carl Th. Dreyer. Tese de Doutorado: PUC-RJ, 2012. 
GODARD, J.-L. Introdução a uma verdadeira história do cinema. São Paulo: Martins Fontes, 1989.

HUIZINGA, J. O declínio da Idade Média. São Paulo: Ulisseia, 1985.

KIERKEGAARD, S. Temor e Tremor. In: Os pensadores. São Paulo: Abril, 1974.

MOURE, J. Du silence au cinéma. MEI - Mediation et Information, Paris, 1998. p. 24-38.

O'BRIEN, C. Rethinking National Cinema: Dreyer's La Passion de Jeanne D'Arc and the Academic Aesthetic. Cinema Journal, v. 35, n. 4, verão 1996.

ORLANDI, E.P. As formas do silêncio: no movimento dos sentidos. $6^{\text {a }}$ ed. Campinas - SP: Editora da Unicamp, 2007

PELEKIN, J. Maria através dos séculos - seu papel na história da cultura. São Paulo: Companhia das Letras, 2000.

PICARD, M. The World of Silence. Nova York: Gateway, 1963.

SADOUL, G. História do cinema mundial. Rio de Janeiro: Martins, 1963.

SIMMEL, G. La signification esthétique du visage [1901]. In: SIMMEL, G. La tragédie de la culture et autres essais. JANKÉLÉVITCH, Vladimir (org.) Paris: Bibliothèque Rivages, 1988.

STEINER, G. O repúdio à palavra. In: STEINER, G. Linguagem e silêncio - ensaios sobre a crise da palavra. São Paulo: Companhia das Letras, 1988.

STORM, O. Introduction. In: DREYER, C. T. Four Screen Plays. Londres: Indiana University Press, 1970. p.12.

VIEIRA, Y. F. A Paixão de Joana D'Arc segundo Dreyer. In: MACEDO, J. R.; MONGELLI, L. M. A Idade Média no cinema. São Paulo: Ateliê Editorial, 2009.

Artigo recebido em 17/11/2020 e aprovado em 17/07/2021. 